\title{
Assessment of Knowledge, Attitude and Breast Self-Examination Practice among Female Students in Sulaimani Polytechnic University
}

\author{
Sarko Masood Mohammed \\ Community Health Department \\ Technical College of Health \\ Sulaimani Polytechnic University \\ Sulaimani - Iraq \\ sarko.mohammed@spu.edu.iq
}

\begin{abstract}
Breast cancer is the most common cancer affecting women all over the world. It is estimated to account for around $25 \%$ of all malignant in women, and incidence shows continuously increasing trend in many countries all over the world. The aim of the study is to determine level of knowledge, awareness, and BSE practice among SPU female students. A descriptive study was conducted a pre- tested questionnaire was used to determine knowledge, attitude and practices of female students in SPU regarding breast cancer and BSE. The face to face interview questionnaire was filled by systematic random sampling to 216 female students from 4 different colleges belongs to SPU, after getting verbal consent to participate voluntary in the study. Data were entered into Epi-data version 3.1.1 and exported to analyse in SPSS version 17. Descriptive analysis was performed and frequencies and percentages were reported. The mean age of participants was 20.7, the study result shows that the knowledge mean score of participants was 3.95 (SD \pm 1.78).181(83.8\%) have information of breast cancer, and $157(72.7 \%)$ have information on breast cancer sign,136(63.0\%) have information on factor that increase change to get breast cancer,150(69.4\%)have information on (BSE),86(39.8\%)have information how to do (BSE),101(46.8\%)have information on mammography .91(42.1\%) practice of (BSE), only 10 ( $4.6 \%)$ female students has performing this examination regularly, percentage of students that did not done mammography was 193 (89.4\%) . only 2 (0.9 $\%)$ performs mammography screening regularly, 18 (8.3\%) have a family member that get breast cancer. Knowledge of female student about breast cancer was at unsatisfactory level. Knowledge of female student about S.B.E was also at unsatisfactory level. Poor practice was observed, regarding BSE. Knowledge regarding mammography was also poor.
\end{abstract}

Key words: breast cancer, knowledge, attitude, practices, Breast self- examination, mammography, college student.

\section{INTRODUCTION}

Breast cancer consider one of the main types of cancer in women worldwide both in developed and developing countries, this increase occurs as a result of variation in healthy life style, increasing the level of life expectancy, and damaging in wildlife environment by urbanization, and adoption of western lifestyle especially by college students age group.

Although some risk reduction might be achieved with prevention, these strategies cannot eliminate the majority of breast cancers that develop in low- and middleincome countries where breast cancer is diagnosed in very late stages. Therefore, in order to improve the rate of breast cancers survival, there should be a good prevention and screening programs for health education with early detection and early treatment [1].

In Sulaimani city there is a lack of awareness program, proper knowledge regarding breast cancer which has a great role in detection of breast cancer in the late stages, with a lack of screening tests such as (BSE), periodic clinical breast examination (CBE) and mammography among university female students. The previous last years has witnessed an increase in breast cancer number, with a lack of sufficient studied regarding this issue in Sulaimani city.

Breast cancer can be defined as a malignant growth of cells and tissues that affect the breast. Which may affect both producing and tubules ducts that carrying milks. Breast cancer can be classified into two main types named tubule and ductal carcinoma. Breast cancer known publically to has a high incidence rate in females; meanwhile it may affect males as well but lesser range than the females. The main causes or contributing factors that thoughts to lead to breast cancer are increasing age, family history, genetic factors, obesity, early menstruation, late menopause and null parity are all recognized as contributory factors [2].

The breast cancer survival rates vary in worldwide, ranging from $80 \%$ in developed countries, to around $40 \%$ in middle income countries and less than $40 \%$ in low income countries. The low survival rates in developing countries may be due to lack of proper prevention and health education programs, with a lack of early detection screening tests such as BSE, CBE and 
mammography with a lack of adequate diagnosis and treatment facilities [3].

Breast self-examination (BSE) has been considered as a most applicable preventive measure that applied by the female herself for detecting an any changes in the breast structures, and it is one of the most commonly recommended strategies for breast cancer screening $[4,5]$. The main goal for both BSE and clinical breast examination (CBE), is to early detection of any palpable nodules. An additional role of BSE is to increase the level of awareness of females regarding normal breast composition [6,7].

The aims of this study were firstly, assessment of level of knowledge of SPU female students regarding breast cancer, secondly, assessment of BSE practices of SPU female students, with evaluation of mammography screening test, and finally, to identify factors associated with better knowledge and practice of SPU female.

\section{LITERATURE REVIEW}

Breast cancer is the most common cancer among women. It is becoming an issue of concern in women's health. The Center for Disease Control mentioned that the best defense against breast cancer morbidity and mortality is early detection of the disease [8].

The best way for reduction of morbidity and mortality from breast cancer will be achieved by providing preventive measures and awareness programs for women in the society, by grating up the level of knowledge that would assist them to change their lifestyle, attitude and behaviors by seeking the available screening methods for early detection of breast cancer. [9].

A study from India-Puducherry report that low level of knowledge among students needs a quick action establish a health education and awareness programs targeting college women to provide breast cancer prevention education [10].

Woman who shows better level of knowledge were participated previously in health education programs about BSE and was likely to practice BSE on routinely [11].

BSE is one of the three screening tests that contributed in the early detection of breast cancer as recommended by The National Cancer Institute and American Cancer Society [9]. The screening cancers activities for early detection include examination, Breast self-examination, clinical breast examination and mammography.

The most cheaper and non-invasive and less painful one is BSE, Clinical breast examination is one of the primary modes of screening for breast cancer. Its effectiveness is dependent upon the skills of health care providers and available facilities. Mammography can reduce mortality rates for women aged 40 to 74 by $25 \%$ [12].

Mortality rates from breast cancer have decreased by 25 to $30 \%$ with early detection, improving quality of screening activities, and enhanced treatment [12]. Detected breast in cancer early stages has a higher chance of treatment [13].

Arabic women currently face a significant risk of high mortality rate from breast cancer due to its late diagnosis "in the advanced stages of the disease [14].

In a study done in Iraq found that almost $75 \%$ of the participants believed that the best way to control breast cancer was through early detection and other possible preventive measures. Most participants (90.9\%) had heard of BSE, only $48.3 \%$ practiced BSE [15].

In Kirkuk University -Iraq reported that $69.9 \%$ of participants have heard about BSE, (42.6\%) reported that they have practices BSE routinely [16]. Another study done in Saudi Arabia reported that the majority (89.2\%) of the participants knew that BSE is recommended to be done monthly [17].

(70.8\%) respondents reporting that they do not know how to perform BSE. However, women strongly agreed that BSE is a method of screening for breast cancer. [18]. Another study done in Jenin reported that the majority of students of age 18-20 years (34\%) had poor knowledge towards BSE while the majority of age above 20 years (19.6\%) had fair knowledge. The majority of poor knowledge level was among first year students then second year respectively (28.9\% and $10.3 \%)$ while the good knowledge was among fourth year then third year respectively (8.2\% and $4.1 \%$ ) [19].

\section{METHODS AND MATERIALS}

\section{Study location:}

Sulaimani, is a one of the major cities of Iraqi Kurdistan region located in the north-east part of Iraq close to the Iranian border.

\section{Study design:}

Study designed to assess the level of knowledge of SPU female students, systematic randomly selected samples of SPU female students done; the study was a quantities study to assess knowledge, attitude and practices (KAP) of SPU female students regarding breast cancer and breast self-examination.

\section{Location of the study:}

The descriptive study was done in different selected colleges in Chwarchra Technical College campus that belongs to Sulaimani Polytechnic University (SPU). All of 4 four colleges were selected from Chwarchra technical college campus to participate in this study.

\section{Duration of the study:}

Initially the research data collection was started from $1^{\text {st }}$ February 2017. The KAP study using the face to face questionnaire simultaneously and lasted until $28^{\text {th }}$ April 2017.

Participants:

Eligibility criteria

\section{Inclusion criteria:}

All female students studying in the selected colleges were eligible to take part in the KAP study.

\section{Exclusion criteria:}

All female employees and male students studying in the selected colleges were excluded.

\section{Data collection:}

Face to face administered questionnaire The KAP study was done using a face to face administered questionnaire including demographic variables, socioeconomic variables, level of education, and years of education, 
knowledge, attitude and practices of female students regarding breast cancer and breast self-examination.

\section{Developing of the questionnaire:}

The face to face administered questionnaires used in the KAP study, consist of 32 questions 6 of which were to assess the level of knowledge, 6to assess the attitude, 7 questions to assess the practices and the rest was sociodemographic data.

\section{Data collection:}

All the data were collected in selected colleges the researcher visited all selected colleges. The data collection for the KAP study was done by starting to fill the face to face administered questionnaire to female students after taking a verbal consent from participants for acceptance to voluntary participation in the study and giving a full explanation about the objective and the aims of the study.

\section{Data processing:}

The questionnaires and has a specific location code that represents a specific college and each questionnaire had a unique ID number which represent the participant number. Questionnaires were sorted every day according to their location code and unique ID number. They were also checked for any missing questions; they were double-checked and entered to the database daily.

\section{Data entry:}

A database was developed in EpiData version 3.1.1 and used for data entry. All questions were precoded. File was exported to SPSS version 17.0 for data analysis.

\section{Statistical methods:}

Analysis of data was performed using Statistical Package for Social Science (SPSS) version 17.0. Descriptive statistics such as means and ranges were computed. Appropriate tests of significance were performed to determine the relationship between sociodemographic variables and the variables related to knowledge, attitude and practice regarding breast cancer and breast BSE. Chi square test was applied to find association between categorical variables. Continues variables were checked using t-test. $P$ values $p \leq 0.05$ were considered statistically significant. The total knowledge score was calculated by summing all knowledge questions.

\section{Ethical considerations:}

The proposal of the study was submitted to scientific committee of the Technical College of Health, and official approval obtained for conducting the study. The study was undertaken in the Chwarchra Technical colleges campus that belong to SPU, A formal permission was obtained from management of the college departments to conduct the study on female students the ethical principles of biomedical research were respected.

\section{Participants consent and confidentiality:}

Before asking participants to complete the questionnaire, they were given a full explanation of the aims and objectives of the study, and they were told that the participation was voluntary, verbal consent was obtained from all participants before administration of face to face administered questionnaire. The privacy and confidentiality of participants were assured by not collecting information on names and other personal identifiers in the questionnaire.

\section{RESULTS}

The sample involved 4 technical colleges belong to SPU selected inside Sulaimani city. Out of an intended sample of 216, 216 completed questionnaires were returned mounting to a response rate of $100 \%$.

Two hundred sixteen 216 female students were agreed to participate voluntary in the study and they were face to face interviewed to fill the questionnaires. Table (1) showed differencepercentage of participants in 4 different selected colleges belongs to (S.P.U). (Technical college of health) participants were 23.1\%, (Technical college of Administration) were 26.4\%, (Technical college of Engineering) were 31\%, (Technical college of Informatics) were $19.4 \%$ simultaneously table1.

Table 1. selected colleges and number of participants

\begin{tabular}{lcc}
\hline College name & \# & \% \\
\hline Technical College of Health & 50 & $23.1 \%$ \\
Technical College of Administration & 57 & $26.4 \%$ \\
Technical College of Engineering & 67 & $31.0 \%$ \\
Technical College of Informatics & 42 & $19.4 \%$ \\
Total & 216 & $100.0 \%$ \\
\hline
\end{tabular}

The mean age of participants was 20.75, maximum number of participants age group $43(19.9 \%) \geq 18$ years of age, while $165(76.4 \%)$ were $19-24$ years old, about $71(32.9 \%)$ of participant students were from first stage, while 2nd and 3rd stages were about 52(24.1\%) for each, marital status of maximum number of selected participants were single, 113(52.3) of participants' residents were comes from urban while only 103(47.7\%) were comes from rural areas. About 96(44.2\%) of participants were having a poor economic status 90(41.5\%) have fair economic status while only 28(12.9\%) were good. $190(88 \%)$ of participant's parents were educated while only $12 \%$ were illiterate table2. 
Table2. Socio-demographic characteristics of participants

\begin{tabular}{|c|c|c|c|}
\hline Total no. = 216 & \# & $\#$ & $\%$ \\
\hline \multirow[t]{4}{*}{ Age } & $\leq 18$ & 43 & $19.9 \%$ \\
\hline & $19-24$ & 165 & $76.4 \%$ \\
\hline & $25-29$ & 7 & $3.2 \%$ \\
\hline & $\geq 30$ & 1 & $0.5 \%$ \\
\hline \multicolumn{4}{|l|}{ Stage (year) } \\
\hline & 1st & 71 & $32.9 \%$ \\
\hline & 2nd & 52 & $24.1 \%$ \\
\hline & 3rd & 52 & $24.1 \%$ \\
\hline & 4th & 41 & $19.0 \%$ \\
\hline \multicolumn{4}{|l|}{ Marital status } \\
\hline & Single & 182 & $84.3 \%$ \\
\hline & Married & 33 & $15.3 \%$ \\
\hline & divorced & 1 & $0.5 \%$ \\
\hline \multicolumn{4}{|l|}{ Residence } \\
\hline & Urban & 113 & $52.3 \%$ \\
\hline & Rural & 103 & $47.7 \%$ \\
\hline \multicolumn{4}{|l|}{ Economic status } \\
\hline & Poor & 96 & $44.2 \%$ \\
\hline & Fair & 90 & $41.5 \%$ \\
\hline & Good & 28 & $12.9 \%$ \\
\hline & Very good & 1 & $0.5 \%$ \\
\hline \multicolumn{4}{|c|}{ Family education } \\
\hline & Illiterate & 26 & $12.0 \%$ \\
\hline & Educated & 190 & $88.0 \%$ \\
\hline
\end{tabular}

The knowledge score of participants were calculated when these knowledge questions were summed to obtain a total score, the total score ranged from 0 to 6 with a mean knowledge score of 3.95 (SD \pm 1.78 ). Table 6 shows comparison of the mean score with various characteristics of participants. Factors which were significantly associated with higher knowledge score of BC. and BSE, were age, marital status, college stage, and residence were statistically significant while parent's education were not. The score was poor, fair, good 25.5\%, 34.7\%, 39.8\% simultaneously table3.
Table3. Association of mean score with various characteristics of the participants

\begin{tabular}{|c|c|c|c|c|c|}
\hline & \# & $\begin{array}{l}\text { Mean } \\
\text { score }\end{array}$ & $95 \%$ CI & $\begin{array}{c}\text { Mean } \\
\text { differenc } \\
\mathrm{e}\end{array}$ & $\begin{array}{c}\text { P- } \\
\text { value }\end{array}$ \\
\hline $\begin{array}{c}\text { Overall } \\
\text { score }\end{array}$ & 216 & 3.95 & $3.80-4.25$ & - & - \\
\hline Age & & & & \multirow{3}{*}{$\begin{array}{c}0.4(0.11- \\
0.78)\end{array}$} & \multirow[b]{3}{*}{0.001} \\
\hline >18 years & 43 & 3.9 & $3.65-4.18$ & & \\
\hline $\begin{array}{l}19-24 \\
\text { years }\end{array}$ & 165 & 4.22 & 4.11-4.32 & & \\
\hline $\begin{array}{l}\text { college } \\
\text { stage }\end{array}$ & & & & \multirow{3}{*}{$\begin{array}{c}0.60(0.1 \\
2-1.32)\end{array}$} & \\
\hline 1st stage & 71 & 3.96 & $3.68-4.02$ & & \\
\hline 4th stage & 41 & 4.35 & 4.3-4.55 & & 0.001 \\
\hline $\begin{array}{c}\text { marital } \\
\text { status }\end{array}$ & & & & \multirow{3}{*}{$\begin{array}{c}1.10(0.6 \\
9-1.73)\end{array}$} & \multirow[b]{3}{*}{0.03} \\
\hline Single & 182 & 4.1 & 3.9-4.25 & & \\
\hline Married & 33 & 4.52 & $4.22-4.65$ & & \\
\hline $\begin{array}{c}\text { Residenc } \\
\text { e }\end{array}$ & & & & \multirow{3}{*}{$\begin{array}{l}1.08(0.5 \\
5-1.82)\end{array}$} & \multirow{3}{*}{0.001} \\
\hline Urban & 113 & 4.48 & $4.30-4.97$ & & \\
\hline Rural & 103 & 4 & 3.84-4.31 & & \\
\hline $\begin{array}{l}\text { Parents } \\
\text { education }\end{array}$ & & & & \multirow{3}{*}{$\begin{array}{c}0.12(0.6 \\
0-0.95)\end{array}$} & \\
\hline Illiterate & 26 & 4.6 & $3.9-4.7$ & & \\
\hline Educated & 190 & 4.77 & $4.62-4.99$ & & 0.6 \\
\hline
\end{tabular}

Knowledge of students toward B.C. and SBE.

35(16.2\%) have no information on breast cancer, while181 (83.8\%) have information on breast cancer, only $77(35.6 \%)$ have information on breast cancer signs, while $157(72.7 \%)$ not have any information on breast cancer signs, about 77 (35.6\%) have information on factors that may increase the chance to get breast cancer, while 136 (63\%) not have any information about it. Only $66(30.6 \%)$ have information on (S.B.E), while 150 (69.4\%) have information on (S.B.E).Eighty six 86(39.8\%) have information on how to do S.B.E, meanwhile 130(60.2\%) don't know how to do it. 115 (53.2\%) never have information on mammography, 101(46.8\%) have information on mammography table 4. 
Table 4. Knowledge of participant regarding B.C. and Breast self-examination.

\begin{tabular}{|c|c|c|c|}
\hline$(n=216)$ & Knowledge & $\#$ & $\%$ \\
\hline \multicolumn{4}{|c|}{ Do you have info. On BC. ? } \\
\hline & Yes & 25 & $11.6 \%$ \\
\hline & No & 181 & $83.8 \%$ \\
\hline \multicolumn{4}{|c|}{$\begin{array}{l}\text { Do you have info on BC? } \\
\text { Signs? }\end{array}$} \\
\hline & Yes & 77 & $35.6 \%$ \\
\hline & No & 157 & $72.7 \%$ \\
\hline \multicolumn{4}{|c|}{$\begin{array}{l}\text { Info. on factors that } \\
\text { increase the chance to get } \\
\text { BC. }\end{array}$} \\
\hline & Yes & 80 & $37.0 \%$ \\
\hline & No & 136 & $63.0 \%$ \\
\hline \multicolumn{4}{|c|}{ Do you have info on BSE? } \\
\hline & Yes & 66 & $30.6 \%$ \\
\hline & No & 150 & $69.4 \%$ \\
\hline \multicolumn{4}{|c|}{$\begin{array}{l}\text { Do you have info. how to do } \\
\text { BSE? }\end{array}$} \\
\hline & Yes & 130 & $60.2 \%$ \\
\hline & No & 86 & $39.8 \%$ \\
\hline \multicolumn{4}{|c|}{$\begin{array}{l}\text { Do you have info on } \\
\text { mammography? }\end{array}$} \\
\hline & Yes & 115 & $53.2 \%$ \\
\hline & No & 101 & $46.8 \%$ \\
\hline
\end{tabular}

\section{Attitude of students toward B.C. and BSE.}

For evaluation of attitude of the of participant in relation to breast cancer, the majority of the applicants had a positive attitude to BSE, weather they believes it is better to get information on breast cancer only127 (58.8\%) has a correct answer, while 83(38.4\%) has wrong answer. About 156(72.2\%) believes that BSE is necessary, and $59(27.3 \%)$ believes it is not necessary to do Breast Self-Examination regularly. 114 (52.8\%) believes it is better to encourage peoples around to do breast self- examination, meanwhile 102(47.2\%) not have interest to encourage people to do breast selfexamination. 137(61.7\%) believes that it is better to do BSE regularly only55 (24.8\%) has a correct answer that the best time to do mammography is post cycle, while 161(74.5) have wrong answer. Only93 (41.9\%) believes that it is better to pass information to other peoples about breast cancer, meanwhile 123(55.4\%) don't think passing information to other people about B.C. and BSE is necessary table5.
Table 5. Attitude and family history of participant regarding $\mathrm{BC}$.

\begin{tabular}{|c|c|c|c|}
\hline$(n=216)$ & Attitude & \# & $\%$ \\
\hline \multicolumn{4}{|c|}{$\begin{array}{l}\text { Believes it is better to get info. On } \\
\text { BC. }\end{array}$} \\
\hline & No & 83 & $38.4 \%$ \\
\hline & Yes & 127 & $58.8 \%$ \\
\hline \multicolumn{4}{|c|}{ Believes BSE is necessary. } \\
\hline & No & 59 & $27.3 \%$ \\
\hline & Yes & 156 & $72.2 \%$ \\
\hline \multicolumn{4}{|c|}{$\begin{array}{l}\text { Believes it is better to encourage } \\
\text { peoples to do BSE? }\end{array}$} \\
\hline & No & 102 & $47.2 \%$ \\
\hline & Yes & 114 & $52.8 \%$ \\
\hline \multicolumn{4}{|c|}{ Believes the best time for mammography is } \\
\hline & Pre cycle & 85 & $38.3 \%$ \\
\hline & During cycle & 76 & $34.2 \%$ \\
\hline & Post cycle & 55 & $24.8 \%$ \\
\hline \multicolumn{4}{|c|}{$\begin{array}{l}\text { Believes it's good to do SBE } \\
\text { regularly. }\end{array}$} \\
\hline & No & 79 & $35.6 \%$ \\
\hline & Yes & 137 & $61.7 \%$ \\
\hline \multicolumn{4}{|c|}{$\begin{array}{l}\text { Believes it is better to pass B.C info. to } \\
\text { others? }\end{array}$} \\
\hline & No & 123 & $55.4 \%$ \\
\hline & Yes & 93 & $41.9 \%$ \\
\hline
\end{tabular}

\section{Practices of students in relation to BSE.}

125(57.9\%) never practice BSE, while 91(42.1\%) practice BSEregularly, 193(89.4\%) never did mammography, 2(0.9\%) didmammography once each year, $11(5.1 \%)$ doing mammography more than one time each year. 2(0.9\%) perform mammography screening every two months, 7(3.2\%) perform mammography screening every six months, while only $4(1.9 \%)$ perform mammography screening annually. Only 91(42.1\%) of participants were practices BSE regularly,81(37.5\%) of participants were performing BSE by themselves, most of participants about 34(15.7\%) performing BSE post cycle, while $31(14.4 \%)$ practicing this examination pre cycle, about 50(23.1\%) encouraging peoples around them to do BSE, 193(89.4\%) of participants have never doing mammography, only $5.1 \%$ of participants did examination more than one time, table 6 . 
Table 6. Practice and family history of participant regarding $\mathrm{BC}$.

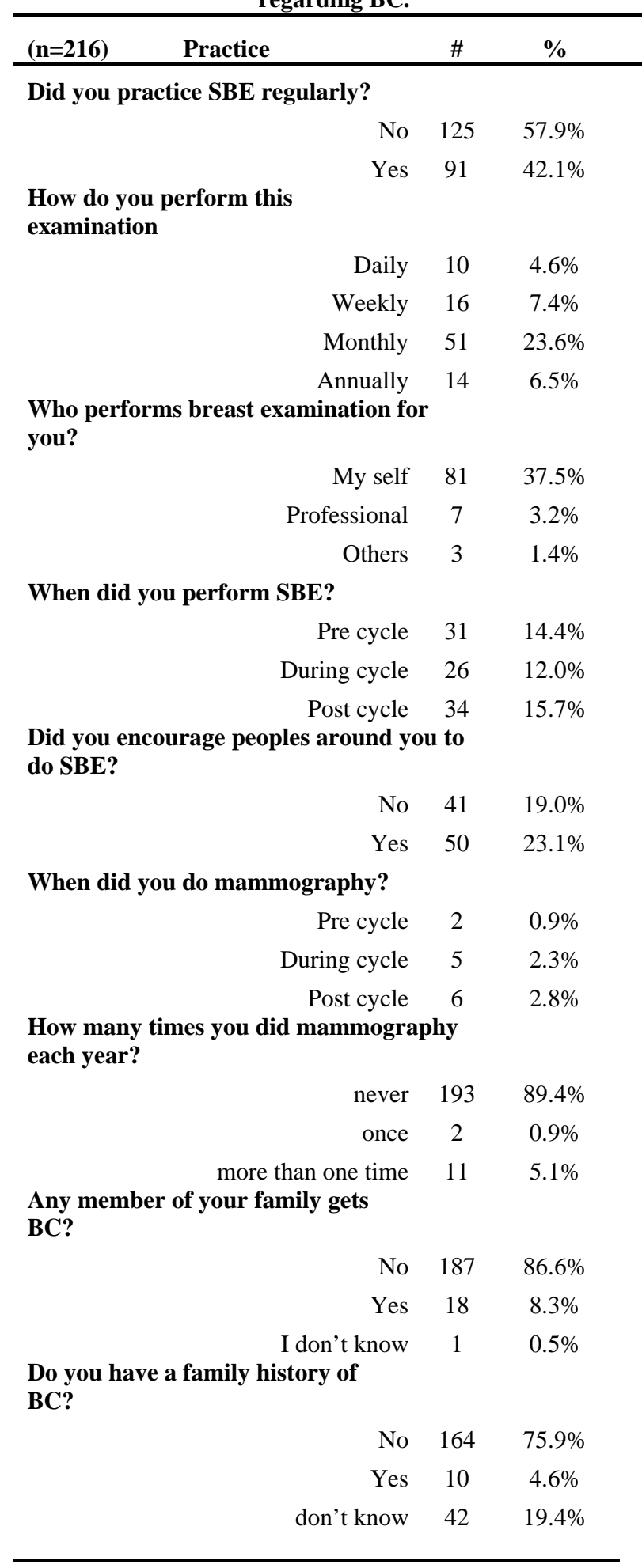

\section{DISSCUSSION}

The present study was conducted in different selected colleges which are belongs to SPU in Sulaimani. The study assessed level of knowledge, attitude, and practices of female students regarding $\mathrm{BC}$, and SBE. The knowledge, attitude and practices of female students were dissimilar among participants; many factors may lead to this difference like the stage in the college, age of participants, marital status, and residence. This study showed that age, marital status, place of residence and college stage were statistically significant factors of better knowledge while parent's education were not. The present study showed that 181 (83.8\%) have information on breast cancer, this result is consistence with a study done in Niagara - India reported that About 90.5\% (314/347) knew about breast cancer [20].

The present study showed that 77(35.6\%) of participants has information on breast cancer signs, which is dissimilar to a study done in Isfahan- Iran revealed that the average of the participants in awareness of breast cancer symptoms (71.57\%) [21]. This difference may be due to a lack of awareness and education sessions in the colleges regarding breast cancer and BSE. The results of this study showed that only $80(37 \%)$ have information about the main factors that may increase the chance to get B.C., which is in consistence with a study done in Isfahan - Iran reported that knowledge of participants about its risk factors (77.15\%) [21].

In the present study136 (63\%) of participants not have information about BSE, this was inconsistence with a study done in Egypt- Alexandria University reported that the level of awareness of breast self-examination was high among the college students [22]. This difference may refer to that the mentioned study was done in nursing college that students have a good medical background about breast cancer. The present study showed that $130(60.2 \%)$ have information about how to perform BSE, it is unlike a study done in Zagazig University, Zagazig, Egypt reported that the college students have deficient knowledge andlow perceptions regarding breast cancer and BSE [23].

The present study results showed that $115(53.2 \%)$ of participants have information on mammography as a screening method for breast cancer, Regarding the attitude of the participants towards BSE, the study results showed that the majority of participants have a positive attitude regarding BC. BSE and mammography, this was consistence with a study done in Jenin in reported that the majority More than three quarters (75.3) of participants had positive attitude towards BSE. No negative attitude has been reported [19]. This positive attitude may relate could be attributed to the mass and social media awareness programs about breast cancer.

The finding showed that about 91(42.1\%) of female students in SPU performs practice S.B.E, this result is inconsistence with a study done in USA revealed that $75 \%$ of female university students were performs SBE [24]. This difference may be due a huge difference in the culture and also refers to low level of health education and low level of knowledge about this examination among SPU female students.

In current study $72.7 \%$ of female student have information about sign and symptom of breast cancer, this result was consistence with a study done among female school teacher in Lagos the information about signs and symptoms of breast cancer about 53.3\%, knew correctly that a mass was commonest recognized symptom of breast cancer [25]. Poor Perform breast self - examination monthly is about $23.6 \%$ while it is comparable to the study done in Pakistan, Aga Khan Hospital Karachi [26]. 75.9\% had negative family history of breast cancer while a study done in Qassim 
region in Saudi Arabia report that $85.6 \%$ had negative family history of breast cancer [27].

In current study only $2.7 \%$ of student knew the appropriate time to do S.B.E is a few days after Menes, these finding are similar studies investigating awareness and knowledge of breast cancer and practice S.B.E among women and university student in Saudi Arabia [28-29].

In the present study $69 \%$ of participant had unsatisfactory knowledge score about S.B.E and 58.9\% of respondent had poor knowledge score a similar result was reported in Iraq [30]. Only $23.6 \%$ of student had satisfactory knowledge about frequency of S.B.E every month, $39.8 \%$ of student knew to how perform S.B.E which was much lower than recorded $66.9 \%$ in Iraq [30]. Seventy six percent $56 \%$ of Nigerian female knew correction time of S.B.E performance [31]. More than 89.4\% never did mammography; the finding of this study is consistent with a study done in Korea [32].

\section{CONCLUSION}

Based on the study results we can conclude that there is low level of knowledge about breast cancer and BSE among female students, there are a poor practices among SPU college students in relation to BSE. There is an urgent need to create awareness programs and sessions about breast cancer in order to great up the level of knowledge of female students.

The importance of establishing education programs regarding breast self- examination among female student in the university, so as to improve the practice SBE. Furthermore, the importance of public awareness on the importance of breast self- examination should be intensified using mass media and the health service personnel to promote breast self- examination.

Female student should possess the accurate knowledge and appropriate attitude about breast cancer; it is recommended the university should be train female student about awareness of importance of mammography as a screening test to early detection of breast cancer. Social media, TV channel can play an important role in dissemination of information about the BSE with other screening test in the early detection of breast cancer.

\section{REFERENCES}

[1] B. Anderson, Y. Smith" Guideline implementation for breast healthcare in low-income and middle income countries: overview of the Breast Health Global Initiative Global Summit 2007, Vol.113(8):2221-2243. 2008. [PubMed].

[2] (WHO), World Health Organization, Cancer Fact Sheet No. 297. (2006). Available

on http://www.who.int/mediacentre/factsheets/fs297/en/index.html).

[3] M. Coleman, M. Quaresma, Cancer survival in five continents: worldwide population-based study (CONCORD), Lancet Oncol, Vol. 9, 730-56.2008.

[4] R. Smith, D. Saslow, K. Sawyer, American Cancer Society Guidelines for Breast Cancer Screening, CA Cancer J Clin; Vol.5,53:141,2003.

[5] T. Jacob, N. Penn, Breast self-examination: knowledge, attitudes, and performance among black women. Journal of the national medical association, Vol.81(7):769,2009.

[6] M. Oussama, K. AtordModjtabai, Guidelines for the early detection and screening of breast cancer, World Health Organization Regional Office for the Eastern Mediterranean Region ,EMRO technical publications, Vol.30, 2006.
[7] M. El Mistiri, I. Rashid, Cancer incidence in eastern Libya: The first report from the Benghazi Cancer Registry, Vol.3.,2003.

[8] CDC, Breast Cancer Screening. Center for Disease Control, Atlanta, GA USA, 2012.

[9] T. McCready, D. Littlewoods, Breast self-examination and breast awareness: A literature review. J ClinNurs; Vol.14(5): 570578.). 2005

[10] C. Jadhav, S. Keerti, Breast tumors and college students: a study of their knowledge, attitude and practice. Indian Journal of Pathology and Oncology. Jul Vol.;4(3):361-4.2017.

[11] O. Abu-Salem, M. Hassan, Breast self-examination among female nurses in Jordan. Shiraz E Med J. Vol. 8(2): 51-57.2007.

[12] V. Mai, T. Sullivan, Breast Cancer Screening Program in Canada: Successes and Challenges. SaludPublica Mex. Vol.51.2009.

[13] A. Bener, H.ElAyoubi, Do we need to maximise the breast cancer screening awareness? Experience with an endogamous society with high fertility. Asian Pac J Cancer Prev. Vol.10(4):599604.,2009.

[14] A. Bener, H. Ayub, Patterns of cancer incidence among the population of Qatar: a worldwide comparative study. Asian Pac J Cancer Prev. Jan_Mar; Vol.9:1, 19_24.2008.

[15] N. Alwan, W. Al Attar, Knowledge, attitude and practice regarding breast cancer and breast self-examination among a sample of the educated population in Iraq. EMHJ - Eastern Mediterranean Health Journal, Vol.18 (4), 337-345, 2012.

[16] N. Alwan, J. Al-Diwan, Knowledge, attitude \& practice towards breast cancer \& breast self-examination in Kirkuk University, Iraq. Asian Pacific Journal of Reproduction. Vol. 1;1(4):308-11, 2012.

[17] D. Nemenqani, S. Abdelmaqsoud, Knowledge, attitude and practice of breast self-examination and breast cancer among female medical students in Taif, Saudi Arabia. Open Journal of Preventive Medicine. Vol.29;4(02):69.2014.

[18] K. Oladimeji, J. Tsoka-Gwegweni, Knowledge and beliefs of breast self-examination and breast cancer among market women in Ibadan, South West, Nigeria. PloS one journal, Vol.25;10(11):2015.

[19] A. Ayed, F. Eqtait, Breast Self-Examination in Terms of Knowledge, Attitude, and Practice among Nursing Students of Arab American University/Jenin. Journal of Education and Practice. Vol.6(4):37-4, 2015.

[20] S. Azubuike, S. Okwuokei, Knowledge, attitude and practices of women towards breast cancer in Benin City, Nigeria. Annals of medical and health sciences research. Vol. 3(2):155-60.,2013.

[21] M. Reisi, S. Javadzade, Knowledge, attitudes, and practice of breast self-examination among female health workers in Isfahan, Iran.Journal of education and health promotion. Vol.2..2013.

[22] H. Abdel Mowla, E. Abdel Aziz, The Effect of Breast SelfExamination Training Program on the Knowledge, Attitude and Practice among Female Nursing Students at Faculty of Nursing, Alexandria University, Egypt,Journal of Nursing and Health Science, PP 42-49,2018.

[23] D. Moustafa, E. Abd-Allah, Effect of a breast self-examination (BSE) educational intervention among female university students. American Journal of Nursing. Vol. 4(4):159-65,2015.

[24] S. Tu, L. Reisch, Breast self-examination: Self-reported frequency, quality, and associated outcomes. J Cancer Educ; Vol.21:175-81.2006.

[25] O. Odusanya, Breast cancer: knowledge, attitudes, and practices of female schoolteachers in Lagos, Nigeria. The breast journal. May; Vol.7(3):171-5.2001.

[26] S. Kumar, A. Imam, Knowledge, attitude and preventive practices for breast cancer among Health Care Professionals at Aga Khan Hospital Karachi. J Pak Med Assoc; Vol.59(7):474.2009.

[27] S. Jahan, M. Al-Saigul, Breast cancer: Knowledge, attitudes and practices of breast self-examination among women in Qassim region of Saudi Arabia. Saudi Med J; Vol.27: 1737-1741.2006.

[28] P. Carney, D. Miglioretti, Individual and combined effects of age, breast density, and hormone replacement therapy use on the accuracy of screening mammography. Annals of internal medicine, Feb Vol.4;138(3):168-75.2003. 
[29] F. Habib, S. Salman, Awareness and knowledge of breast cancer among university students in $\mathrm{Al}$ Madina $\mathrm{Al}$ Munawara region. MEJC; Vol.1: 159-166.2010.

[30] N. Alwan, W. Al-Attar, .Knowledge, attitude and practice regarding breast cancer and breast self-examination among a sample of the educated population in Iraq. EMHJ .Vol. 18 No. 4 2012 .

[31] O. Charles, Awareness, Knowledge and Practice of Breast-Self Examination amongst Female Health Workers in A _Nigerian Community. Sudan JMS Vol. 3, No.2,2008.

[32] S. Lee, E. Sim, Factors affecting periodic screening behaviors for breast cancer among hospital nurses. Korean J. Women Health Nurse. Vol.16(4): 390-398.2010.

\section{ACKNOWLEDGEMENT}

Thanks to Bokan Ahmed, Shnar Ibrahim and Rezana Mustafa for their assistance in data collection. 